\title{
Influencias asiáticas en la búsqueda del confort en el periodo colonial chileno: de la alfombra al estrado
}

\author{
Asian influences in the search for comfort in the \\ Chilean colonial period: from the carpet to the estrado
}

\section{Resumen}

Autor:

Mauricio Baros Townsend* mbartown@gmail.com

* Universidad de Chile

Recibido: 03/Mar/2021 Aceptado: 18/Jun/2021
E n las sobrias casas coloniales chilenas e hispanoamericanas se destacaba una pieza de mobiliario de uso diario: el estrado, un objeto que tendría su origen en la textilatría que surgió tempranamente en el Asia Central y en la cultura islámica y cuyo mayor exponente fue la alfombra, la cual realizó un camino al mundo europeo a través del comercio flamenco. Este trabajo pretende demostrar el origen oriental del estrado, a través de su tránsito asiático y luego europeo hasta hacer su arribo en América, y también destacar el rol social que adquirió al constituirse en un mobiliario esencialmente femenino dentro del espacio de la casa colonial chilena.

Palabras clave: estrado; confort; vivienda; Hispanoamérica; Periodo Colonial.

Abstract:

In the austere Chilean and Spanish-American colonial houses, a piece of furniture for daily use stood out: el estrado. Element that would have its origin in the textilatry that arose early in Central Asia and in Islamic culture and whose greatest exponent was the carpet, which made a way to the European world through the Flemish trade. This work aims to demonstrate the eastern origin of the estrado, through its Asian and later European transit until it arrived in America, and also to highlight the social role it acquired by becoming essentially feminine furniture within the space of the especially Chilean colonial house.

Keywords: estrado, comfort, home, Hispanic America, Colonial Period. 


\section{Introducción}

El confort es el estado subjetivo de experimentar un interior "satisfactoriamente concebido" tanto como un atributo material del propio interior. Para Kerr, el imaginario del confort precede a su planificación. (Rice, 2007, p. 67)

Cuando Rice afirma que la idea o imagen respecto del confort precede a su planeamiento está de alguna manera proponiendo que existirían dos aspectos del mismo: un confort que se anhela, que se desea, y otro que se adquiere, el material. La primera categoría cae en el mundo de los imaginarios del confort, y la segunda en los hechos materiales que lo posibilitan. Por consiguiente, la idea del confort y el hecho mismo, si bien se producen conjuntamente, no necesariamente son equivalentes.

La ideación del confort moviliza, según Bachelard, a toda una constante ensoñación y anhelo de reposo (Bachelard, 2000), en tanto, en lo referente a la concreción misma de este reposo, esta condición se construye o alcanza a través de las cotidianas transacciones del individuo con su habitar. Así, mientras en la primera aproximación no hay límites a la especulación, sueño o deseo, la cual es alimentada constantemente por nuevas ideas y anhelos de reposo y confort, en el caso segundo se cae en el pragmatismo de la disponibilidad de los medios materiales.

Curiosamente estas actitudes se encuentran muy bien representadas en algunas piezas del mobiliario que formaron parte fundamental de las viviendas chilenas e hispanoamericanas desde fines de la Colonia hasta los albores de la Modernidad, como lo es, por ejemplo, el estrado. El propósito de este artículo es abordar este objeto, entendiéndolo como un elemento en el cual se corporeizó la idea y la construcción del confort, tal como fue concebida por la sociedad chilena en el Periodo Colonial, hasta comienzos del Período Republicano, cuando terminó por desaparecer de los hogares chilenos.

El estrado era la plataforma elevada sobre el suelo y cubierta por alfombras, en donde principalmente se sentaban las mujeres (Figura 1). Se constituyó en una pieza fundamental del mobiliario de las viviendas coloniales hispanoamericanas. Su origen es claramente oriental, y forma parte de la herencia hispanomusulmana no siempre reconocida por la historiografía americana (Irigoyen-García, 2016).

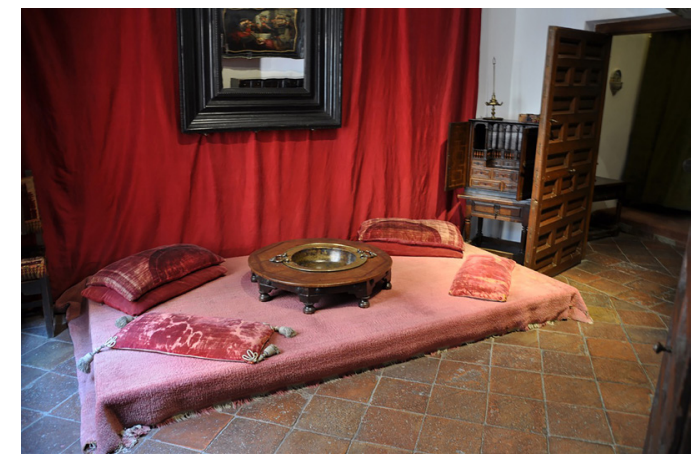

Figura 1: Estrado en la Casa Museo de Lope de Vega. Madrid

Fuente: Fotografía del autor (julio 2017)

Cabe, entonces, investigar el camino que realizó esta pieza de mobiliario, proveniente de la cultura oriental, examinando su recorrido a través de diversos referentes para arribar en los salones coloniales chilenos. "Es el análisis de los propios objetos lo que permite revelar los sutiles movimientos de poder en juego." (Gerritsen y Rielo, 2015, p. 2. Traducción del autor).

El planteamiento hipótetico es que el estrado estaba ligado a los usos y las costumbres transmitidas inconscientemente, pero que encontraron una nueva utilidad y funcionalidad en América, lo cual reflejó, de alguna manera, tanto hábitos existentes como heredados, convirtiendo a este objeto en una de las piezas más importantes en las casas coloniales. En consecuencia, en este artículo se propone estudiar la particular manera que tuvo la sociedad chilena de entender el confort a través del estudio del estrado. Para ello, se abordarán los dispositivos que permitieron la construcción del confort en la Colonia, centrados en el uso y variaciones que tuvo esta pieza de mobiliario en el ámbito nacional y en la América colonial.

La investigación tuvo como resultado la constatación de la importancia que esta pieza de mobiliario adquirió en los hogares coloniales chilenos; en segundo lugar, se pudo establecer el vínculo del cuál provienen parte de las costumbres de la sociedad colonial en lo que respecta al confort material de la época, y su origen en la cultura islámica.

\subsection{Estado del arte}

La historiografía chilena, en lo concerniente al ámbito arquitectónico y la cultura material de la época colonial, resulta escasa. Las mayores aportaciones están en el ámbito del estudio de los roles sociales y políticos de los diversos actores sociales de la época, abordados ampliamente por Sagredo y Gazmuri en la Historia de la Vida Privada en Chile (2005), y por Stuven y Fermandois en la Historia de las Mujeres en Chile (2010). La austeridad de la sociedad colonial es posible de verificar en la obra de Valenzuela Márquez (2007), en donde se da cuenta principalmente del ambiente urbano colonial.

Desde el ámbito de la cultura material, están por un lado las aportaciones de Cruz de Amenábar, con su obra El traje: transformaciones de una segunda piel (1996) sobre la vestimenta colonial, pero quizás más 
importantes resultan las investigaciones en el ámbito del epistolario y testamentario de la época, que si bien han estado centradas principalmente en el ámbito religioso, resultan un aporte para la constatación de la existencia del mobiliario colonial, como la abordada en el caso de este trabajo (Kordić, 2005; Ruiz Valdés, 2005).

Ante la casi total ausencia de un corpus respecto de mobiliario colonial en Chile, resultan imprescindibles las referencias hispanas de obras como La Casa Medieval en la Península Ibérica (Diez y Navarro, 2015), y en el caso del mobiliario, la obra de María Paz Aguiló, quien realiza un completo inventario de los muebles hispanos de los siglos XVI y XVII; de la misma forma, en el caso de Sudamérica, aparece la obra El Mueble Colonial en las Américas, de Bomchil y Carreño (2011), que si bien aborda el caso argentino, es lo más próximo al caso de estudio tratado.

Por último, desde el punto de vista de la representación artística, obras como Behind Close Doors (Aste et al. 2013), dan un esbozo del imaginario colonial de las casas hispanoamericanas en general.

\subsection{Métodos}

Este trabajo es resultado de una investigación continua en el tema, desarrollada en el Centro de Estudios Arabes de la Universidad de Chile. De manera sintética, esta investigación se apoya en un método inductivo, que tiene por etapas: observación, registro y análisis de casos.

a. En la primera etapa, a partir de la revisión bibliográfica de fuentes en un marco temporal comprendido entre los siglos XVIII y XIX, se establecen e identifican los casos de estudio. De esta indagación se detectaron una serie de objetos del ámbito de la cultura material, cuyo origen, según diversas fuentes, tenían un claro referente oriental: ellos eran las alfombras, el estrado y el sofá. Para efectos de esta investigación se abordaron los dos primeros.

La documentación revisada incluyó el corpus literario, epistolario, y testamentario chileno de la época, en donde fue posible detectar información relevante respecto del tema de estudio. Los documentos revisados se obtuvieron a través de instituciones universitarias y públicas, principalmente, lo que incluyó información en formato tanto físico como digital, obtenido de los sitios institucionales correspondientes.

b. La segunda etapa de registro se realizó en dos fases. Una primera fase consiste en una visita a terreno a países y regiones relacionados con los referentes de los objetos de estudio, principalmente de la cultura islámica (Irán 2015, 2019, Uzbekistán 2017, Cáucaso 2018, Turquía 2019), en donde fue posible corroborar tanto la existencia pasada como el uso actual de los referentes estudiados. En una segunda fase se procedió a una visita a terreno a países como Perú (2018) y Bolivia (2019), principalmente con el objetivo de verificar la presencia de los objetos estudiados en los sitios relacionados con la preservación de la cultura material colonial que estos países poseen, e indagar en las fuentes bibliográficas existentes en ellos. Las visitas produjeron abundante información escrita, gráfica y fotográfica. c. La última etapa consiste en el análisis y comparación de los datos recogidos en las visitas, contrastados con la información recopilada en la primera etapa y su complementación con nuevo material bibliográfico que permitió precisar los argumentos e hipótesis de la investigación, y establecer las principales problemáticas a tratar en este trabajo, que a continuación se exponen.

La revisión bibliográfica, tanto de documentos de la época como de obras que tratan el período, junto con la verificación en terreno (casas-museo), permitió constatar no solo la existencia de esta pieza de mobiliario-aún en uso en los países orientales visitados- en los hogares coloniales chilenos. Sumado a lo anterior fue posible verificar la morfología que estos asumían, aspecto que suele ser pobremente descrito en las fuentes bibliográficas, y que de alguna manera se logra esclarecer con el registro gráfico que aquí se acompaña.

\section{Vestir el espacio y vestir el cuerpo: una antropología del confort}

Precisamente, el vestido se convierte en la primera proyección hacia el exterior; la ornamentación de los muros es otra, evidenciada por la idea de que las personas no se adaptan a sus paredes, sino que "sus paredes deben adaptarse a ellas". Es decir, las habitaciones se decoran como una proyección exterior del yo (...) Entendido como un reflejo del cuerpo, o una proyección del cuerpo doméstico en su entorno, el entorno se convierte en una extensión del yo (Taylor, 2006, p. 5. Traducción del autor)

Desde el punto de vista antropológico, la acción del cubrimiento remite a los orígenes mismos de la arquitectura. En esta perspectiva, es interesante rescatar los siguientes aspectos: observar cómo el cubrir precede al vestir. En efecto, el cubrir ${ }^{1}$ es una acción siempre básica y primera, pues su propósito es el de proteger, cuyo étimo así lo explica. El cubrir es una acción que busca proteger desde el ámbito geográfico hasta el personal e íntimo, y por ello también es un ocultar. Por lo tanto, el cubrir es una acción anterior, primera, antes que el vestir, pues primero protege y luego viste. Se cubre el espacio y se cubre el cuerpo. De esta forma, cubrir siempre posee un significado más amplio (Rueda, 2015). Solo en una etapa ulterior, el cuerpo pasa de cubrirse a vestirse. En el cubrir el traje se convierte, a su vez, en un soporte de significados no referidos al cuerpo sino a la persona. El vestir $^{2}$ en tanto está referido al cuerpo: su sujeto es el cuerpo mismo.

Así como el cuerpo se cubrió y luego se vistió, esto se traspasó a los interiores del propio habitar. Cuando los

${ }^{1}$ Cubrir, viene del latín cooperire (cubrir enteramente) y de su participio coopertus nos llega cubierto. Con-/co- (conjuntamente, globalmente) y operire (cubrir) contrario de aperire (abrir). Proviene del indoeuropeo wer/ uer. Cerrar, cubrir. De la misma raíz provienen warjan (proteger), además de guarir, guarecer, garaje, garita. Weren (garantir) Garantizar, garante, garantía. Warnjan (proveer) guarnir, guarnecer.

${ }^{2}$ Vestir proviene del latín vestire, y este de la raíz indoeuropea wes ues, que significa ropa, indumentaria. 
diversos paramentos ya cumplieron fielmente la función del cubrir, una vez que esta primera acción es superada deviene el vestir; es por ello que en la antigüedad se pensaba que los espacios estaban desnudos y había que vestirlos como se vestía al cuerpo.

Esto se hizo evidente en el medioevo europeo y en la América colonial, en donde la precariedad económica y la escasez de mobiliario condujeron a una gran austeridad en sus construcciones, con un mínimo de alhajamiento, haciendo que las habitaciones pareciesen desnudas (Ruiz Valdés, 2005). A esto hay que agregar que el tamaño de las construcciones aumentaba la sensación de carencia de equipamiento interior.

Precisamente, esta carencia y necesidad de vestir los espacios, motivará la necesidad de adquirir los productos textiles: tapices, alfombras, cortinas, etc., los cuales, en su conjunto, vendrán de algún modo a suplir las necesidades de confort de estas sociedades preindustriales. Es preciso considerar que esta necesidad tradicional de cubrir los espacios provenía de un antecedente de raigambre oriental y que había sido transmitido a la Europa Medieval y posteriormente trasladado a América (Diez y Navarro, 2015).

Según Golombek (1980), en el origen nómade de la cultura islámica residiría una mentalidad textil. Efectivamente, la necesidad de habitar diversos entornos para buscar mejor confortabilidad sin duda fue el origen de todo un corpus textil que, tempranamente, surge en la cultura preislámica, que había recibido la influencia cortesana de otras culturas, como la bizantina y la persa. Estas convertirán a estos cubrimientos en vestiduras, transformando los simples tejidos en elementos iconóforos, en tanto se constituyen en verdaderas superficies de representación (Alpers, 2020), iniciando así una tradición en el desarrollo de los textiles, que tanta fama le han dado a la cultura islámica en este rubro.

Mientras que estas superficies de representación de mundo islámico nacieron ligadas al ámbito religioso y político, en el mundo occidental se asociaron principalmente a la era de la cartografía iniciada por los holandeses, quienes, a través de sus mapas, atlas, cartas, etc., entrarán en contacto con estas otras superficies de representación, tal como son los textiles en Oriente (Oledzka, 2016). Es interesante señalar que todos estos medios estarán presentes en los interiores arquitectónicos retratados por los pintores de la época, en donde en una misma pintura se pueden observar las cartas, los mapas y las alfombras. Esta capacidad iconófora de transportar significados del mundo texti también existía en la América precolombina, cuya función se aproximaba más al uso islámico que al europeo.

\subsection{De la cultura textil a la cultura visual: el nacimiento del imaginario del lujo}

Una de las acepciones de la palabra técnica es la de tejer y fabricar ${ }^{3}$. A partir de este origen técnico se construirá toda una tradición artesanal en el mundo islámico existente hasta el día de hoy, y en muchos países de la región. Semper, en 1851, establecía que el origen de la arquitectura se encontraba en los textiles, representados en las tiendas de campaña de las tribus nómadas (Potvin 2015).

Si la cultura occidental proviene del cultivo de conocimiento abstracto, en la oriental subyace este origen técnico y textil. En el mundo islámico es posible apreciar claramente dos vertientes en su producción cultural: una proveniente de las altas esferas del poder y cultivada por el ambiente cortesano e intelectual, y otra propia de un sustrato popular (Graves, 2016). En esta última los orígenes de su cultura provendrían más del hacer que del pensar, de lo técnico más que de lo especulativo. Este origen cultural ligado a lo material hará que sus expresiones artísticas estén más próximas a la naturaleza, y que su relación con su entorno sea mucho más cercana. Ellos, los islámicos, vivían en un mundo que no estaba dado, sino que había que construir entendiendo el construir en tanto tejer el mundo, para así poder habitarlo, pues el tejido proporcionaba cubrimiento y protección. Este origen textil o tectónico quedará plasmado para siempre en el arte islámico en general, desde sus vestimentas hasta su arquitectura.

La asociación entre el lujo y el Oriente comienza a través del comercio textil flamenco, porque las alfombras, los tapices, las sedas, etc., eran los productos más apetecibles y más fácilmente transportables. La geografía exótica, según Schmidt (2015), presentaba el mundo como un producto atrayente, una imagen del mundo a modo de mercancía. El comercio holandés convirtió el exotismo en una mercancía. No solo lo hizo más asequible, sino que, además, lo democratizó, puesto que estos productos ya no eran solo adquiridos por una elite, sino que pudieron llegar a un número más amplio de personas de diferentes clases sociales, y esto fue crucial para el desarrollo comercial de la época. Se presenta lo exótico como algo agradable, atractivo y consumible. Esto despertó un gusto por lo asiático que va a verse reflejado en los ricos interiores eclécticos de la época (McNeil y Riello, 2016).

Se produce así una democratización en la economía y en la cultura de la época, no solo porque ahora los productos podían ser comprados por mucha gente, sino además porque estos eran ampliamente representados en diversos medios, como la pintura, la cerámica o los tapices. $Y$ esto tiene su origen en que el imaginario de lo exótico es eminentemente visual y pictórico. En esta dimensión, su origen de entrada en Europa tendrá lugar a través de los productos textiles y la cerámica.

En definitiva, los flamencos realizaron el tránsito de una cultura textil a una cultura visual, al desligar estas superficies de representación de su contenido cultural original, es decir, social, tribal, étnico, etc., para hacer prevalecer entonces solo los aspectos materiales de estos artículos, lo que les permitirá transformarse en simples mercancías, desnudas de todo el contenido simbólico que ellas portaban (Campen, Corrigan y Diercks, 2016).

Los tejidos más finos provenientes de Oriente reemplazan a la antigua lana de amplio uso por el mundo europeo. Con estos nuevos textiles surgió todo un universo de formas y colores más llamativos y ricos que los antiguos

3 Técnica de la raíz indoeuropea * teks: tejer, fabricar, asamblar. DRAE juntar, unir, carpintería. 
diseños. El problema reside en que la geografía del exotismo, para la Europa de la época renacentista, tendrá límites mucho más maleables y ambiguos que los límites geográficos o políticos, puesto que dentro de este imaginario también se incluirá todo lo procedente del recién descubierto continente americano, pasando así lo americano a formar una parte más del depositorio exótico del cual se alimentaba el arte y la moda europea de esos siglos (Peck y Bogansky, 2013).

Este imaginario comenzará a ampliarse para incluir elementos ya no solo textiles, sino también cerámicas, especies, café, té, chocolate, etc., que se comerciaban desde muy antiguo. No importaba su origen dentro de la esfera extraeuropea: todos ellos cargaban el mismo nivel de exotismo para el mundo europeo. Es en este contexto que lo exótico comenzará a ser asociado con el lujo.

Como se sabe, el nacimiento del lujo se asoció con lo extraño y lo exótico, características que ya estaban vinculadas en tiempos romanos con los objetos provenientes de Oriente, llámese Persia, Egipto o Siria. "Las importaciones de Oriente formaban parte de la definición clásica y occidental del lujo. Livio sostenía que Roma se había contaminado con lujos asiáticos, importados de Grecia y Oriente" (Berg y Eger, 2003, p. 8. Traducción del autor.)

Desde la Edad Media, las alfombras orientales han sido reconocidas en Occidente como accesorios mobiliarios prestigiosos. Fueron un objeto que pasó de ser objeto de uso a una mercancía -tal vez una de las primeras en hacerlo- porque su origen estuvo en el nomadismo mismo, y porque han sido uno de los primeros objetos domésticos en viajar grandes distancias. Por otra parte, las alfombras poseían el doble propósito de otorgar confortabilidad y exotismo. En efecto, este carácter exótico que tuvieron en Occidente se produjo principalmente porque se desvincularon de su origen nómade y de la función simbólica que originalmente poseían. Precisamente ese desconocimiento o falta de información respecto de su origen, resultaba funcional a la transformación del objeto en mercancía, un rasgo que les permitió readaptarse al uso que les quisieron otorgar sus nuevos propietarios.

En esto reside justamente el valor y atractivo de las alfombras como productos orientales. Su distancia geográfica y simbólica les otorgaba un valor estético por el exotismo de su origen, y un valor funcional porque podían adaptarse a nuevos usos. Esta cualidad que las convertirá en productos de ese temprano capitalismo no se terminará nunca; por el contrario, será posteriormente acrecentada con la aparición del orientalismo. Probablemente de ahí proceda el interés que despertaron en retratarlas como objetos y la mistificación que se hizo de ellas. Esta mistificación se produce porque el origen se mantiene como algo incierto. Las cosas exóticas pasan a pertenecer a un Oriente ambiguo e imaginario, un Oriente que es claramente un producto del orientalismo más que de la realidad. Esto aumenta su halo de exotismo, pero, al mismo tiempo, es un impedimento para aproximarse a su verdadero origen. Es decir, se facilita el consumo y se entorpece el entendimiento.
La readaptación que sufren estos objetos en cuanto mercancías les permitió servir para múltiples propósitos, entre ellos vestir los interiores arquitectónicos. Así, muros, camas, mesas, suelos, etc., se cubrieron de cortinajes, manteles, tapices, alfombras, ingresando masivamente a los hogares flamencos de la época. No obstante, este será un escenario muy específico y anticipatorio de lo que se vivirá en el resto de Europa recién hacia el siglo XIX, debido a que las condiciones materiales, especialmente del mundo mediterráneo, distaban mucho del exotismo que aquí estaba surgiendo. Por consiguiente, alejándonos de las latitudes de los ricos interiores flamencos y aproximándonos a la realidad colonial americana nos encontramos con un panorama muy distinto (Bauer, 2002).

\section{La cultura material en la}

\section{Colonia}

El mobiliario en el mundo de precariedad y escasez medieval se convirtió en un símbolo de estabilidad. Gracias a su condición de durabilidad y permanencia más allá de la vida de sus propios dueños, era un ancla para el equilibrio emocional del sujeto. Esta característica surgida en Europa y traspasada a América, será mantenida durante todo el periodo colonial, cuya sociedad se estructuraba a través de una serie de costumbres y rutinas heredadas -en parte inconscientemente- de la cultura hispanomusulmana. "...un ámbito islamizado en el que ideas, doctrinas, narraciones, etc., circulaban adaptándose a las distintas exigencias de estos, pero manteniendo un aire de familia" (Fierro, 2008, p. 96).

Esta sucesión de hábitos y costumbres tendieron tanto a integrar a la comunidad como también a diferenciarla socialmente. Resultaba evidente que una sociedad pequeña y cerrada como la colonial necesitaba de una integración social de la élite, especialmente frente a lo externo. Si bien existían estratos sociales definidos, tendían a consolidarse aún más fuertemente a través de lazos de parentescos y el establecimiento de una serie de protocolos, hábitos y relaciones sociales destinados a reafirmar esta unidad.

Simmel (2005) alude a la emocionalidad propia de un mundo rural y que es opuesta a la intelectualidad de la ciudad. Es algo que parece adaptarse perfectamente a la realidad colonial, pues esta emocionalidad es lo contrario a la ostentación pública, y es mantenida -como señala el autor- a través de costumbres y rutinas que caracterizaron a la sociedad colonial, rasgos que se manifestaban indudablemente en sus modos de reunirse y comportarse. Se trata, pues, de un mundo donde priman los modos por sobre las maneras y protocolos. En esta dimensión entendemos modos como aquello que etimológicamente alude a lo medido, a lo corporal, a lo táctil, ya que aquí no se han construido-al menos endogámicamente- las distancias sociales que posteriormente impondrá el protocolo de una civilidad más urbana que surgirá con la República. 
En efecto, las maneras republicanas adoptadas más tarde fueron construcciones sociales, mientras que los modos coloniales, entendidos como hábitos, comportamientos, etc., están relacionados con lo inmediato, lo íntimo, lo cercano, lo doméstico, cuyo origen muchas veces se escapa a toda clasificación, pues son transmitidos, a menudo inconscientemente, de generación en generación (Vicuña, 2012). El paso de la Colonia a la República puede ser entendido como un tránsito de los modos a las maneras. Por lo tanto, si se dice modos de sentarse, se refiere al contacto del cuerpo con el asiento; en tanto maneras, es una estructura aprendida, intencionada y aplicada con un fin.

Según Csikszentmihalyi y Halton (1981) la mayoría de los pueblos tradicionales suelen enfatizar el yo integrado o social a expensas de la singularidad personal, mientras que en occidente prevalece el yo individual y diferenciado. Tal vez de aquí surge una diferencia fundamental: la sociedad colonial tendió a la integración y la republicana a la diferenciación desde el punto de vista de los usos. Los modos de comportamiento, si bien heredados inconscientemente, de alguna forma sirvieron, en el periodo colonial, para integrarse más que para diferenciarse, lo cual queda claramente explícito en el uso del estrado en las casas coloniales, que puede ser entendido como un asiento compartido, en tanto que el diván, en el futuro, lo será individual. Es por ello que la alfombra, y posteriormente el estrado, expresan de algún modo no solo la movilidad de la gente de la época, sino también la costumbre de compartir e integrarse: de ahí la indefinición de la superficie en donde sentarse. Son elementos del mobiliario que no diferencian, sino que reúnen, y esta costumbre tiene obviamente un antecedente oriental.

\subsection{Los modos orientales}

El denominado estilo de vida "a'I orientale", se refería a una vida que se desarrolla cerca del suelo, o directamente a ras de suelo, según Sadan (1976). Este modo oriental no es sino una acción que manifiesta un origen nómade y de aquí proviene la importancia de la alfombra, la estera, el tapiz, o cualquiera de las formas que existe para separarse del suelo desnudo. Esta costumbre, a pesar de las mejoras materiales que se produjeron con el tiempo, se ha conservado por siglos en la cultura islámica, perdurando hasta en el presente.

El sentarse en el suelo o sobre una plataforma elevada es una costumbre oriental, practicada en un amplio abanico geográfico que se extiende desde China hasta el norte de África. Este hábito se mantiene en muchos de estos países y es posible comprobarlo en el uso del $k o ̈ s k^{4}$ en Turquía, Irán y países del Asia Central, o del kang ${ }^{5}$ chino (Figura 2).

Hasta el siglo XIII la voz "estrado" no denomina al conjunto de muebles que conforman una pieza de recibir. Sin embargo, está ya formada con anterioridad debido a la asimilación de las costumbres de la admirada cultura cordobesa. Allí y en Oriente se emparamentaban suelos y paredes y se tomaba asiento bien en la postura turca de piernas cruzadas, bien recostándose en alfombras, colchones y cojines ("sarir", "martaba", "mirfaga", "miswar", "numruq", etc.) de diverso tamaño (Rodríguez y Gisbert, 1990, p. 42)

En el caso específico de Andalucía, el antecedente más inmediato de la alfombra es el sarir musulmán, que habría aparecido entre los siglos XII y XIII. De Andalucía pasó a América, en donde la costumbre, especialmente de las mujeres, de sentarse en el suelo, no solo en la casa, sino también en el templo, propició tempranamente el

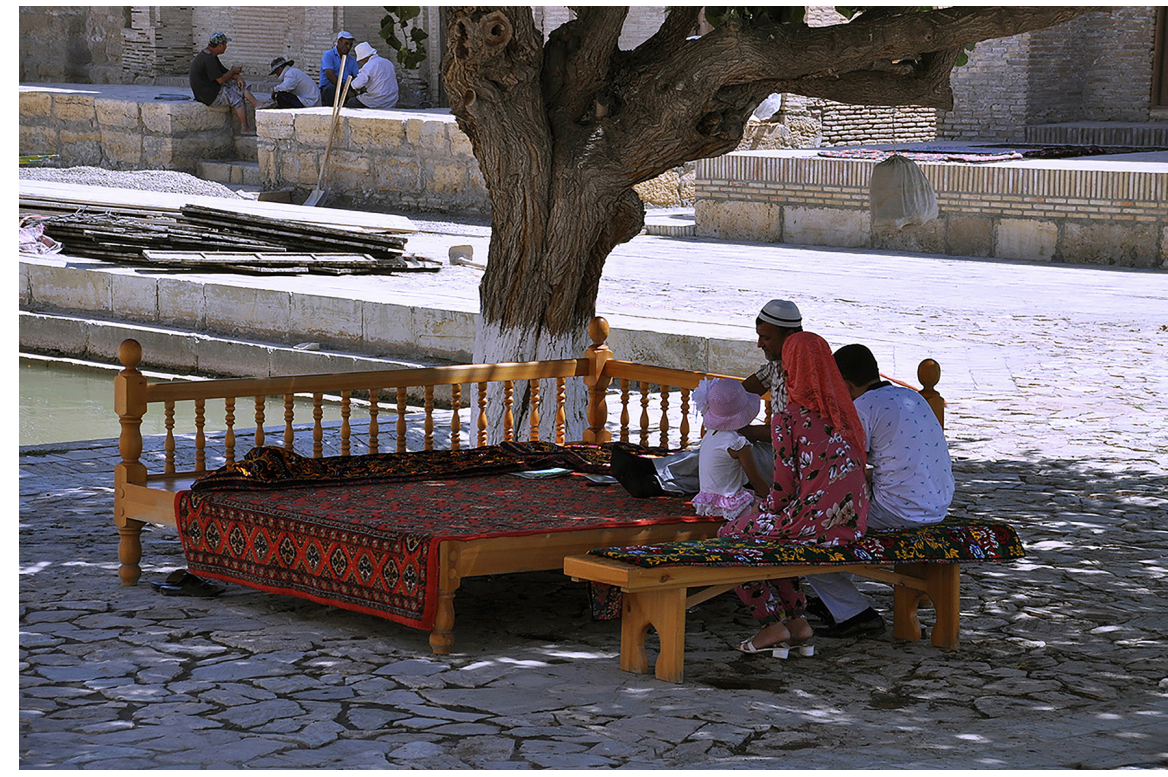

Figura 2: Plataforma elevada utilizada en toda el Asia Central, Irán y Turquía para descansar. En este último país recibe el nombre de kösk. Bujara (Uzbekistán) Fuente: Fotografía del autor (julio 2017)

${ }^{4}$ Kösk: plataforma elevada enfrentando el hayat (galería o patio en e primer piso) ocupada en las casas otomanas tradicionales que servía de asiento.

${ }^{5}$ Kang: asiento en forma de plataforma elevada calefaccionada por abajo utilizado en las casas del norte de China.
${ }^{6}$ Sarir: cama, sofa, trono, etc. El término ha tenido diversas connotaciones a través del tiempo en el uso islámico, pero siempre conserva como denominador común el ser un mobiliario para permanecer en posición sedente, reclinada o acostada. 
uso de alfombras o esterillas para poder realizar tal acción y sin ensuciarse. Los más desposeídos siguieron utilizando la antigua tradición indígena de sentarse en el suelo desnudo.

El estrado no es sino la continuación de estas prácticas, que evolucionaron hacia la creación de una plataforma que posibilitaba una mayor separación del suelo y de las incomodidades que este podía transmitir, como la humedad, la suciedad, los insectos, etc. Además, sobre e mismo se colocaban los elementos textiles que lo cubrían completamente. Sin embargo, la complejidad que tiene este elemento es que algunas veces parece designar un espacio y otras un mueble.

Esto implica que no hay un solo tipo de estrado, sino que puede constituirse desde una especie de banco adosado a las paredes de la habitación, o una tarima que ocupaba gran parte de ella, o la habitación misma en donde se situaba este objeto, tal como se aprecia en las descripciones sobre él en los diversos países hispanoamericanos. En lo que sí parece haber acuerdo es en designar finalmente con tal nombre no solo a la tarima elevada sino a todo el conjunto de muebles que le acompañaba. Por otro lado, es posible encontrar en algunos autores la referencia a diversos tipos de estrado al interior de una vivienda. Según Aguiló (1993) habrían existido tres tipos de estrados: 'de respeto', 'de cumplimiento' y 'de cariño'. Sin embargo, la alusión a la existencia de distintos tipos de estrado parece solo existir en el ámbito literario, siendo más un producto de la ficción que de la realidad, al menos en lo que concierne a la realidad americana.
En su origen el estrado estaba asociado con los espacios de recepción, pues en el ámbito islámico el sentarse en el suelo no era una prerrogativa solo de las mujeres, sino que era compartido por todos. La separación por géneros estaba referida a espacios más que a mobiliarios. La mayor parte de los espacios, tanto públicos como privados, en las casas islámicas contaban con un mobiliario similar. En el caso de Andalucía se restringió tempranamente a una mayor especificidad del mismo. Según Abad, hasta el siglo XIII el estrado era compartido indistintamente por hombres y mujeres, y recién en el siglo siguiente se transforma en un reducto femenino, "reservado para la labor de aguja, la oración, la lectura o la tertulia" (Abad, 2003, p. 376). Es interesante notar que en la época posreconquista de la España cristiana, junto con conservar este modo oriental de sentarse, el estrado se feminiza para pasar a ser un espacio destinado principalmente a las mujeres, una costumbre que será transmitida a la América colonial.

Es importante señalar que el estrado, pese a lo modesto que podía ser en su estructura, estaba asociado con las viviendas, principalmente de la elite, y por lo tanto se constituía en uno de los bienes que expresaban el lujo dentro de una familia. En el caso de Chile, a diferencia de resto de América, sin duda este despliegue de productos importados era mucho menor, como lo demuestra la existencia de una arquitectura menos ostentosa que el resto de América. Sin embargo, la presencia del estrado también se relaciona con el confort y el ocio que en tiempos coloniales eran un privilegio principalmente de las élites, las cuales podían permitir que sus mujeres pasasen gran parte del día en el estrado, socializando con sus cercanos (Figura 3).

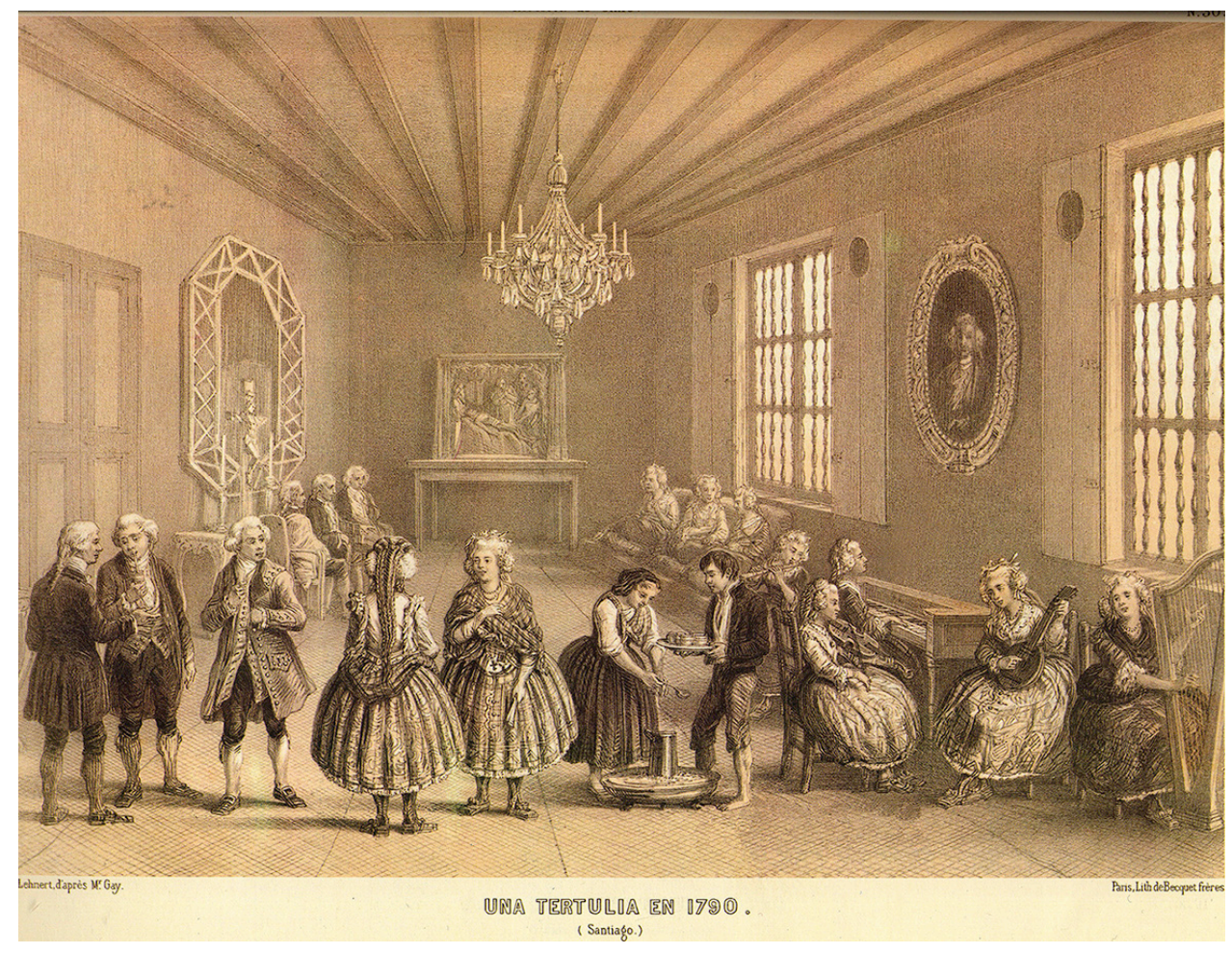

Figura 3: Una tertulia en Santiago, Claudio Gay, 1790

Fuente: Atlas de la historia física y política de Chile. Paris: Imprenta de E. Thunot, 1854 
El ambiente que producía esta espacialidad se prestaba, además, para largas estancias y el consumo de brebajes asociados a las mismas. En el caso de Chile, este brebaje por excelencia lo constituía el mate, una bebida que dada sus características se prestaba para ser degustado en una estancia protegida y que permitiera una larga permanencia, como exige la costumbre. A ello se agregaba el brasero, siempre encendido para calefaccionar el espacio, y el agua utilizada para el mate, junto con algunos comestibles.

\section{El pequeño universo femenino del estrado}

"El estrado femenino estaba dotado de mobiliario que comprendía un variado número de objetos de pequeño tamaño como cojines, almohadas, mesitas, escritorios, costureros, cofres, cajas, arquetas, la rueca y un brasero; era un ámbito bellamente trabajado con objetos muy elaborados" (López, 1996, p. 154).

El estrado, además de la plataforma y las alfombras que lo cubrían, poseía un mobiliario complementario asociado con él, como señala López, y que era de muy delicada manufactura, lo cual contribuía a dar la idea de lujo a mismo espacio. Debe tenerse en cuenta, que el lujo en el mundo colonial se asociaba principalmente con la mujer (Rosas Lauro, 2019). Todos los objetos que comprendía el estrado eran realizados especialmente para este lugar por ello recibían el apelativo de "muebles de estrado". Su apariencia los hacía aparecer miniaturizados, por lo que, en ciertas ocasiones, se les denomina muebles ratones, debido a que debían adaptarse tanto a la posición sedente o reclinada de su usuario como a la escala de estrado mismo. Afirma Bomchil (2011) que el mobiliario ratón, por su tamaño, poseía un carácter exclusivamente femenino (Figura 4).
Este universo miniaturizado genera una característica peculiar, constituyendo un mundo privado propio de la mujer. Igualmente, venía acentuado por la separación que producían otros objetos, como cortinajes o bardas, que separaban al estrado del resto de la habitación. Sin duda que esta miniaturización igualmente permite diversas lecturas respecto de su propósito o efecto.

Justamente la miniaturización les otorga un aspecto ficcional a las cosas, pues las desliga, de alguna manera, de la realidad y las integra a un espacio y tiempo propios, en donde las cosas permanecen apartadas de la historia que las rodea, como lo ejemplifican los juguetes, convirtiéndolas en una experiencia domesticada (Steward, 2012). La miniaturización, en consecuencia se transforma en una forma de protección y aislamiento de la mujer en su entorno, en un universo femenino propio, cual casa de muñecas, como espacios dentro de espacios, rasgos privativos de estos reductos de reclusión física y quizás mental, en los cuales estuvo la mujer largo tiempo en Occidente. "Estaban cautivas en el espacio, sujetas a otros y aprisionadas en sus cuerpos" (Araya, 1999, p. 82). (Figura 5).

La contrapartida de este escenario es el sentimiento de posesión que se le otorga a la mujer por sobre los objetos del estrado. El término utilizado usualmente en testamentos e inventarios es ajuar del estrado, con el sentido de una pertenencia únicamente femenina. Cuando la mujer tenía la posibilidad de donar el estrado, entre otros bienes testamentarios, sin duda le otorgaba manifiestamente el sentido de pertenencia que ella podía ejercer sobre este espacio. Tal como señala el testamento de Mariana González en 1602: “Declaro que la dicha de mi madre me dio en vida un estrado y una colcha que tengo: quiero y es mi voluntad que se le dé a mi hermana María Madalena: mando se le dé" (Kordić,

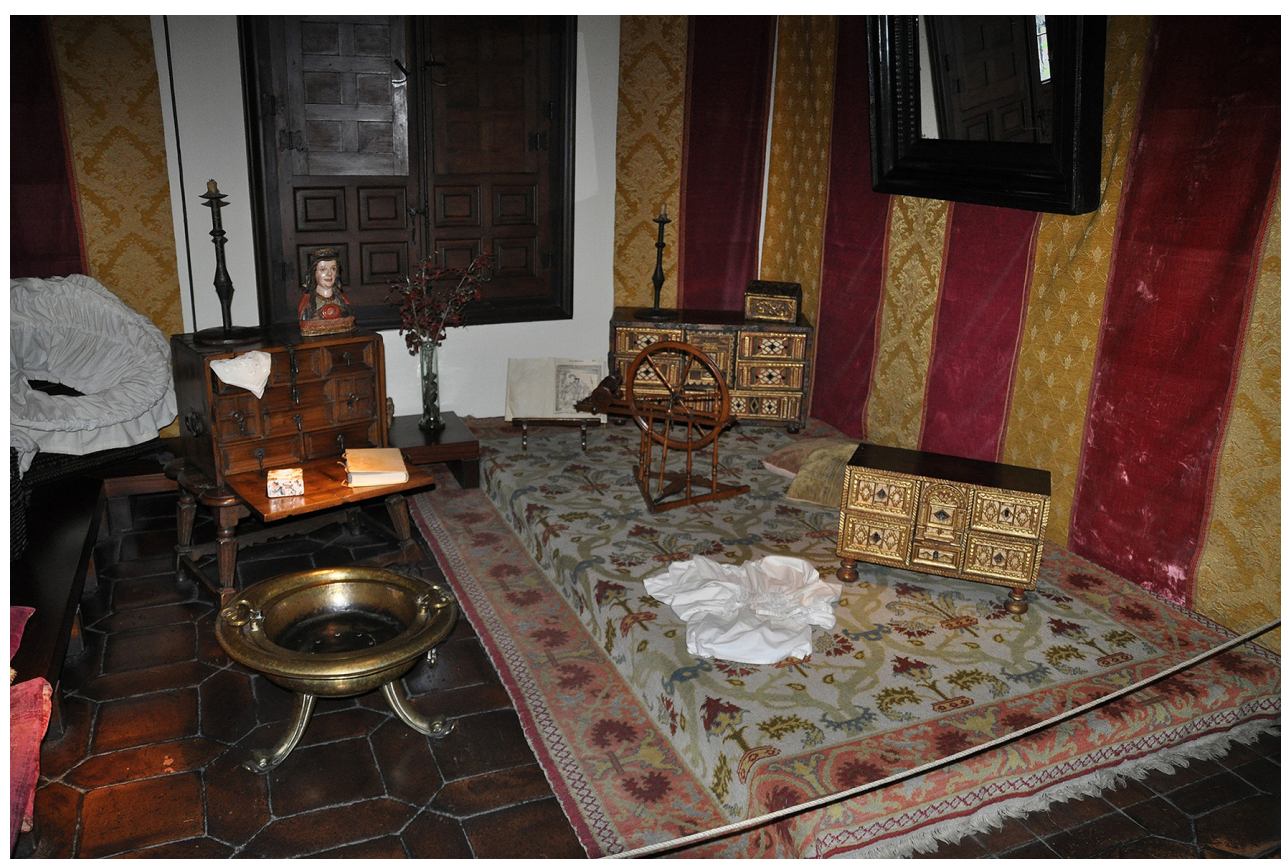

Figura 4: Estrado en la Casa Museo de Cervantes, en Alcalá de Henares. Aquí es posible observar los denominados muebles ratones que solían acompañar al conjunto del estrado

Fuente: Fotografía del autor (julio 2017) 


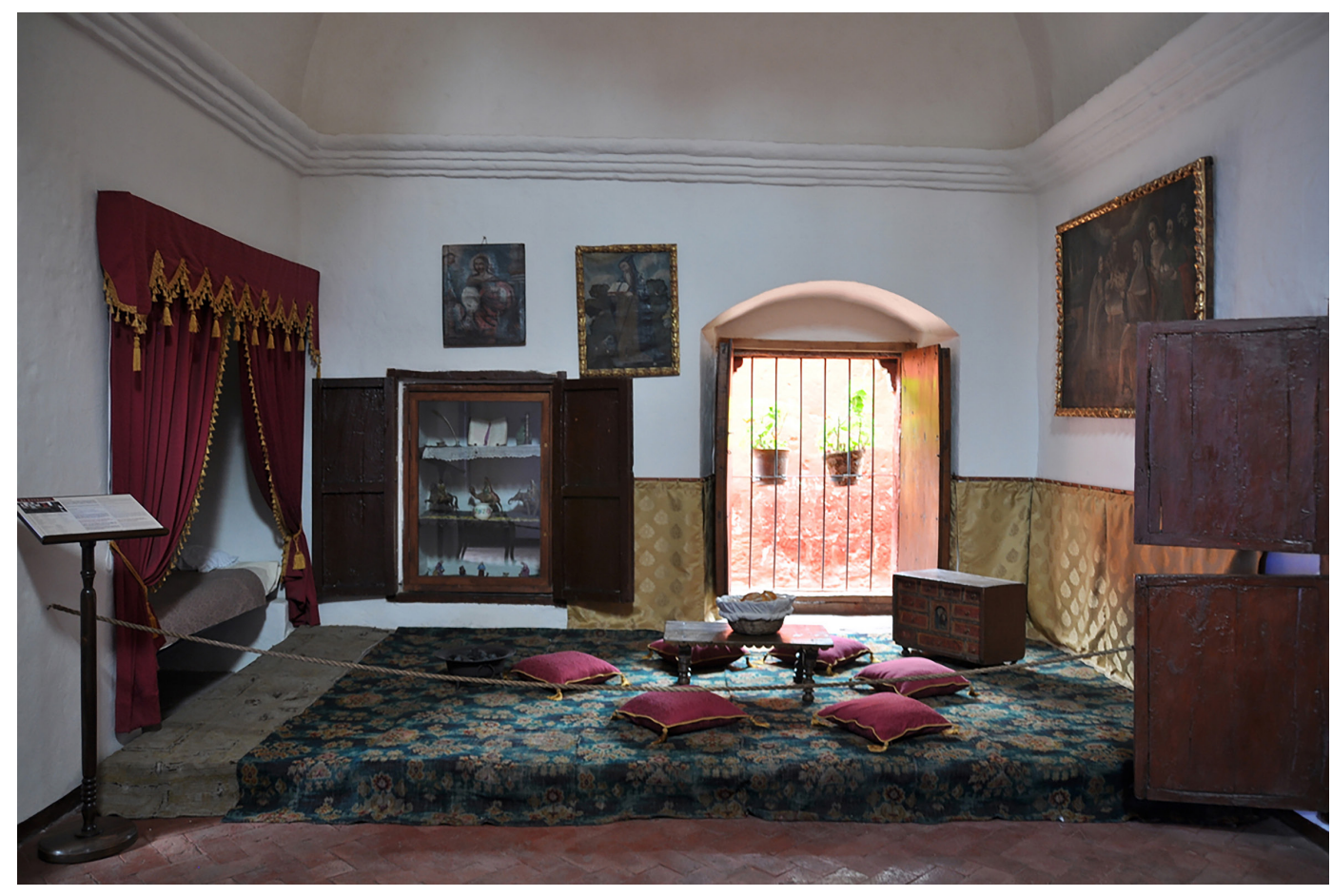

Figura 5: Estrado de una celda del convento de Santa Catalina en Arequipa

Fuente: Fotografía del autor (febrero 2018)

2005, p. 95). Por lo tanto, estamos ante un espacio de reclusión y de posesión de la mujer dentro del espacio de la vivienda. En esta perspectiva es necesario diferenciar el estrado dentro de la casa colonial con el complemento funcional que cumplirán los textiles orientales a los que nos hemos referido anteriormente.

Es indudable que este revestimiento textil del estrado contribuía no solo a darle uniformidad, sino que además lo caracterizaba como un espacio dentro de otro espacio. Se convertía en el espacio más 'vestido' de la casa-si así lo pudiésemos designar-, similar a las características de los ropajes de sus usuarias. Ambos son elementos de identidad y protección del cuerpo y del espacio femenino. Asimismo, la procedencia de los textiles tendía a darle un carácter exótico al espacio conformado por el estrado, el cual resultaba muy diferente a la austeridad que caracterizaba al resto de los espacios.

Por otro lado, la extensión y la separación del estrado en el espacio no era uniforme. Algunas fuentes mencionan que incluían textiles colgantes que lo separaban del resto de la habitación, otras mencionan a los balaustres bajos y otras señalan que no había ninguna separación aparte de su elevación.

Del jardín pasamos inmediatamente á la sala, donde conforme á la costumbre, una estrecha ventana enrejada dejaba pasar una luz muy escasa. Al lado de la ventana, un largo banco cubierto con una especie de grosero tapiz de Turquía, hecho aquí, ocupa casi todo el largo de la pieza, y adelante hay una plataforma de madera, que llaman estrado, que se levantan unas seis pulgadas del suelo y tiene cerca de cinco pies de ancho, cubierto con un tapiz de la misma clase: el resto de piso es de ladrillos pelados. Una hilera de sillas de respaldo alto ocupa el costado opuesto de la pieza (Graham, 1916, p. 160).
En esta cita, lo que menciona María Graham como "sala", en el Chile colonial se lo denominaba 'cuadra'.? En algunas partes de América el estrado se asoció con el dormitorio, pero en Chile se situaba principalmente en la 'cuadra', la cual se consideraba el espacio de recepción más importante de la casa, en donde se recibía a las visitas y se desarrollaban las tertulias. Se solía en ocasiónes denominar "cuadra de estrado", a la habitación en donde este estaba situado (Danwerth y Duve, 2019). La cuadra solía ser la habitación de mayor tamaño y se localizaba en las casas coloniales de tres patios, entre el primero y el segundo patio.

También, en el caso chileno, se colocaban sillas para que se sentaran los hombres, siendo el estrado de uso solamente femenino. En algunos lugares de América, al parecer como México, hubo estrados en las habitaciones privadas, situadas muchas veces en un nivel superior de la vivienda (Farwell, 2010). Esta costumbre es muy similar a la que ocurre en las casas islámicas de algunas ciudades del norte de África o de Egipto, en donde la habitación de las mujeres suele situarse en un piso superior, de preferencia junto a un balcón y con vistas al exterior. Estas habitaciones solían estar ricamente alhajadas.

Desde el punto de vista de la utilidad, el estrado junto con su alhajamiento se constituía, sin duda, en uno de los espacios más cómodos para permanecer especialmente largas horas en él. Es importante notar cómo el estrado anticipa lo que será posteriormente la aparición de otro mobiliario de origen oriental: el sofá. El sofá implicará un cambio que estará asociado, en Chile, a la Belle Époque chilena, que condujo a una transformación en la arquitectura, mobiliario y costumbres del país.

${ }^{7}$ Cuadra: sala o pieza espaciosa. DRAE. 


\section{Discusión y conclusiones}

Al respecto, si bien el estrado se constituyó en uno de los espacios de sujeción de la mujer en el ambiente doméstico del mundo colonia (Araya, 2008), por otro lado también fue una conquista, pues se convirtió en el único espacio manifiestamente femenino dentro de la casa. Es necesario, sin embargo, preguntarse por qué permaneció esta costumbre de usar el estrado en la sociedad latinoamericana, mientras que otras costumbres no fueron transmitidas a la América Colonial. Habría varias respuestas al respecto. Por una parte, el recostarse o reclinarse era un hábito que existió en la antigua Grecia y Roma, y era considerado como símbolo de estatus. Algunos autores como Roller (2006), sostienen que esta costumbre tendría su origen en Oriente. La práctica de reclinarse se habría transmitido desde Oriente Próximo a la península itálica, a través de mundo griego, a fines del periodo arcaico. Por otra parte, era del todo placentera la comodidad que proporcionaba esta posición semirecostada, acompañada por las alfombras, los cojines, las almohadas, los taburetes, etc., que componían el espacio. Por lo demás, también se argumentaba que, para las mujeres, con los vestidos abultados que se utilizaban en la época colonial, les era más cómodo y agradable sentarse en el estrado que en una silla. Es importante señalar que la comodidad que proporcionaba el estrado pudo ser una de las razones de su permanencia tanto en España como en América. Precisamente, América se habría adelantado a Europa en la búsqueda del confort que comenzaría una vez llegada la llustración.

Es dable mencionar que el estrado era considerado una pieza de mobiliario de las casas de los estratos altos, y que la escasez de mobiliario era una condición general para toda la sociedad colonial. Farwell (2010) afirma que, a la llegada de los españoles a América, se encontraron con que el uso de alfombrillas o esteras para sentarse en el suelo era típico entre las poblaciones indígenas. Las sillas solo las utilizaban las personas con autoridad o los miembros de la clase alta, pues eran símbolos de poder y estatus. En el mundo precolombino existió esta tradición de sentarse en el suelo o sobre elementos textiles, pero es poco probable que la élite, en donde solía aparecer e estrado, imitara las costumbres indígenas, principalmente porque tendía a diferenciarse. No obstante, habría que considerar que las clases sociales de menores ingresos sí hacían uso de esta costumbre, tal como se puede verificar en fuentes gráficas y literarias de la época.

Por consiguiente, el estrado se constituyó en una significativa herencia de los usos transmitidos por la cultura hispanomusulmana, resultó funcional en la América Colonial y se adaptó a las costumbres e idiosincrasia de los diferentes escenarios de la América Hispana. Asimismo, el estrado se adecuó y se mantuvo en un elemento primordial que reflejó la posición de la mujer dentro de la casa colonial y, por extensión, del mundo colonial. De este modo, el estrado se convirtió en uno de los primeros reductos específicamente femeninos dentro de la vivienda colonial, formando parte de una conquista física y cultural de la mujer sobre un espacio y un mundo que evidentemente era prioritariamente masculino.
El estrado tuvo su término hacia fines de la Colonia y comienzos de la República. La aparición de otros muebles, como el diván o sofá, también de origen oriental, señaló un nuevo modo de relacionarse y de imaginarse el Oriente y, en rigor, el orientalismo.

Cómo citar este artículo/How to cite this article: Baros Townsend, M. (2021). Influencias asiáticas en la búsqueda del confort en el periodo colonial chileno: de la alfombra al estrado. Estoa. Revista de la Facultad de Arquitectura y Urbanismo de la Universidad de Cuenca, 10(20), 65-75. doi: 10.18537/est.v010.n020.a06

\section{Referencias bibliográficas}

Abad, C. (2003). El estrado: continuidad de la herencia islámica en los interiores domésticos zaragozanos de las primeras cortes borbónicas (1700-1759). Artigrama (18), 375-392.

Aguilo Alonso, M. (1993). El mueble en España siglos XVIXVII. Ediciones Antiqvaria.

Alpers, S. (2020). El arte de describir. El arte holandés en el siglo XVII. Ampersand.

Araya Espinoza, A. (2008). Un imaginario para la mezcla. Mujeres, cuerpo y sociedad colonial. En S. Montecino (Ed.) Mujeres chilenas: fragmentos de una historia. Catalonia.

Araya, A. (1999). Cuerpos aprisionados y gestos cautivos: el problema de la identidad femenina en una sociedad tradicional (Chile 1700-1850). Nomadias: series monográficas, el género y las mujeres, aportes historiográficos, 1, 71-84.

Aste, R. (Ed.). (2013). Behind closed doors: Art in the Spanish American home, 1492-1898. New Orleans Museum of Art.

Bachelard, G. (2000). La poética del espacio. Fondo de Cultura Económica.

Bauer, A. (2002). Somos lo que compramos. Taurus.

Berg, M. y Eger, E. (2003). Luxury and Pleasure in Eighteenth-Century Britain. Palgrave MacMillan.

Bomchil, S. y Carreño, V. (2011). El Mueble Colonial de las Américas. Maizal Ediciones.

Campen, J., Corrigan, K. y Diercks, F., (2016). Asia in Amsterdam. Yale University Press.

Crowley, J.E. (2003). The Invention of Comfort. Johns Hopkins University Press.

Cruz O., I. (1996). El traje: transformaciones de una segunda piel. Ediciones Universidad Católica de Chile. 
Csikszentmihalyi, M. y Halton, E. (1981). The Meaning of Things: Domestic Symbols and the Self. Cambridge University Press.

Danwerth, O. y Duve, T. (2019). Normatividades e instituciones eclesiásticas en el virreinato del Perú, siglos XVI-XIX. Max Planck Institute for Legal History and Legal Theory.

Diez, J. E. y Navarro, P. J. (2015). La casa medieval en la península Ibérica. Silex Ediciones.

Fierro, M. I. (2008). Las huellas del islam a debate. En Roldán Castro y M. M. Delgado Pérez (Eds). Las huellas del islam (pp. 73-96). Universidad de Huelva.

Gerritsen A. y Riello G. (2015). Writing Material Cultural History. Bloomsbury.

Golombek, L. (1988). The Drapped Universe of Islam. En P. Soucek (Ed.) Content and Context of Visual Arts in the Islamic World. Pennsylvania State University Press.

Graham, M. (1953). Diario de su residencia en Chile (1822) y de su viaje al Brasil (1823). Editorial del Pacífico.

Graves, M. S. (2016). Islamic art, architecture and material culture: New perspectives. BAR Publishing.

Irigoyen-García, J. (2016). "Como hacen los moros a los cristianos": Raza, género e identidad cultural en "Tarde llega el desengaño" de María de Zayas. Revista canadiense de estudios hispánicos, 40(2), 357-370.

Kordić, R. (2005). Testamentos coloniales chilenos. Iberoamericana/ Vervuert.

López, M. del P. (1996). El estrado doméstico en Santafé de Bogotá en el Nuevo Reino de Granada. Ensayos: Historia y Teoría del Arte, (2), 135-172. https://revistas. unal.edu.co/index.php/ensayo/article/view/46450

McNeil, P. y Riello, G. (2016). Luxury a rich history. Oxford University Press.

Oledzka, E. (2016). Medieval \& Renaissance interiors in illuminated manuscripts. British Library

Peck, A. y Bogansky, A. (2013). Interwoven globe. The world Textile Trade 1500-1800. Thames\&Hudson.

Potvin, J. (2015). Oriental Interiors, Design, Identity and Space. Bloomsbury Academic.

Rice, Ch. (2007). The emergence of the interior. Routledge.

Rodríguez Bernis, S. y Gisbert Marco, I. (1990). Mueble español: estrado y dormitorio. M.E.A.C. Dirección General de Patrimonio Cultural.

Roller, M. (2006). Dining Posture in Ancient Rome: Bodies, Values, and Status. Princeton University Press.

Rosas Lauro, C. (2019). Género y mujeres en la historia del Perú: del hogar al espacio público. Fondo Editorial de la Pontificia Universidad Católica del Perú.
Rueda, J. O. (2015). Bekleidung. Los trajes de la arquitectura. Fundación Arquia.

Ruiz Valdés, J. (2005). Cultura material y sociedad colonial: Un estudio desde documentos notariales. Santiago 16901750. Universidad de Chile.

Sadan, J. (1976). Le Mobilier au Proche-Orient médiéval. Brill Archive.

Sagredo Baeza, R. y Gazmuri Riveros, C. (2005). Historia de la vida privada en Chile. Taurus.

Schmidt, B. (2015). Inventing Exoticism, Geography, Globalism and Europe's Early Modern World. University of Pennsylvania Press.

Simmel, G. (2005). La metrópolis y la vida mental. Revista Bifurcaciones: revista de estudios culturales urbanos, (4), 1-10

Steward, S. (2012). On Longing: Narratives of the Miniature, the Gigantic, the Souvenir, the Collection. Duke University Press Books.

Stuven Vattier, A. y Fermandois, J. (2011). Historia de las mujeres en Chile (1a. ed.). Aguilar.

Taylor, M. (2006). Furniture is a kind of dress: interiors as projection of self. En T. McMinn, J. Stephens, y S. Basson. (Eds). Contested Terrains, XXIII Annual Conference of the Society of Architectural Historians (pp. 530-555). Proceedings.

Valenzuela Márquez, J. (2007). Historias urbanas: homenaje a Armando de Ramón. Universidad Católica de Chile.

Vicuña, M. (2012). La política de las formas. Universum, 27(2), 237-247. 